the values on placebo $(P<0.001)$ (table IV). But there were no significant differences in blood pressure at any time of day between the once-daily and the thrice-daily regimens.

TABLE IV-Systolic and diastolic blood pressures $(\mathrm{mm} \mathrm{Hg})$ according to treatment and time of day (mean of values for 12 patients)

\begin{tabular}{|c|c|c|c|c|}
\hline & & $\begin{array}{l}\text { Placebo } \\
\text { period }\end{array}$ & $\begin{array}{c}\text { Thrice-daily } \\
\text { regimen }\end{array}$ & $\begin{array}{l}\text { Once-daily } \\
\text { regimen }\end{array}$ \\
\hline $\begin{array}{l}8 \text { am standing } . . \\
8 \text { am recumbent } \\
11 \text { am recumbent } \\
3 \mathrm{pm} \text { recumbent } \\
9.30 \mathrm{pm} \text { standing } \\
9.30 \mathrm{pm} \text { recumbent }\end{array}$ & $\begin{array}{l}\cdots \\
\because \\
\because \\
\cdots\end{array}$ & $\begin{array}{l}157 \cdot 0 / 107 \cdot 8 \\
151 \cdot 799 \cdot 5 \\
180 \cdot 0115 \cdot 6 \\
173 \cdot 5 \cdot 112 \cdot 9 \\
169 \cdot 709 \cdot 1 \\
160 \cdot 8 \cdot 102 \cdot 1\end{array}$ & $\begin{array}{l}145 \cdot 297.8 \\
140 \cdot 490 \cdot 0 \\
155.599 .8 \\
149 \cdot 695.6 \\
150 \cdot 6.95 \cdot 2 \\
142.888 .5\end{array}$ & $\begin{array}{l}145.796 .8 \\
143.090 .3 \\
159.399 .3 \\
147.796 .8 \\
150.395 .8 \\
143.789 .9\end{array}$ \\
\hline Day's average $\ldots$ & .. & $165 \cdot 4107 \cdot 8$ & $147 \cdot 3 / 94 \cdot 5$ & $148 \cdot 394 \cdot 8$ \\
\hline
\end{tabular}

$S^{2}$ for systolic blood pressure: 49.3; $S^{2}$ for diastolic blood pressure: $26 \cdot 2$ (from ANOVA).

\section{Discussion}

Our study aimed at comparing the degree of $\beta$-blockade and the hypotensive effects produced by a single daily dose of $300 \mathrm{mg}$ metoprolol with those produced by three daily doses of $100 \mathrm{mg}$ of metoprolol. The single daily dose was not given in the morning or evening, which are the usual times, but at noon, since this enabled us to study the patients within a few hours before and after the single daily dose. A single daily dose of $300 \mathrm{mg}$ was chosen since this can reduce the exercise heart rate by $35^{\circ}$ " (table III), which is close to the maximum $\beta$-blockade that can be achieved in man." Our findings confirm the $\beta$-blocking activity of metoprolol. ${ }^{4}$

Douglas-Jones et $a l^{6}$ have shown that atenolol, which has a plasma half life of nine hours, decreases the blood pressure and is still effective 24 hours after it has been taken. They did not, however, compare a once-daily with a thrice-daily regimen and they measured the blood pressure only at one time of the day. Bühler et $\mathrm{al}^{7}$ gave a single daily dose of a slow-release form of oxprenolol $(3.5 \mathrm{mg} / \mathrm{kg} /$ day $)$ and found the hypotensive action as effective as that of a thrice-daily regimen with propranolol $(3.3 \mathrm{mg} / \mathrm{kg} /$ day). The two treatment periods were, however, not randomised and blood pressure measurements were not made throughout the day.
We found that the $\beta$-blocker metoprolol, which has a shorter plasma half life $\left(2.9\right.$ hours $\left.^{5}\right)$, produced a hypotensive effect throughout the day with a single daily dose of $300 \mathrm{mg}$ or with a thrice-daily regimen of the same amount. The hypotensive effect tended to be more pronounced and less fluctuating at different times of the day during the thrice-daily regimen, but these differences were not significant.

In conclusion, although a single daily dose of $300 \mathrm{mg}$ of metoprolol can maintain detectable plasma metoprolol concentrations throughout the day, the peak concentration is five times the lowest concentration, even during long-term treatment (table II). Consequently, a single daily dose of $300 \mathrm{mg}$ of metoprolol can produce a significant degree of $\beta$-blockade throughout the day but its degree varies on average from $17^{\circ}$, two hours before the single dose to $35^{\circ}$ " two hours after it (table III). A single patient showed variations in 3 -blockade from $7^{\circ}{ }^{\circ}$ in the late morning to $36^{\circ}{ }^{\circ}$ in the early afternoon. If a steady degree of $\beta$-blockade is the therapeutic goal a single daily dose of $300 \mathrm{mg}$ metoprolol cannot therefore be recommended.

Both the once-daily and the thrice-daily regimens significantly reduce blood pressure throughout the day, but the thrice-daily regimen tends to have a more potent and less fluctuating hypotensive action. The differences in the hypotensive effects of the two regimens are not statistically significant, however, so that a single daily dose of metoprolel may be used if the hypotensive effect is the only therapeutic goal.

\section{References}

Ervik, M, Acta Pharmacologica et Toxicologica, 1975, 36, suppl No 5, p 136

2 Reybrouck, T, Amery, A, and Billiet, L, fournal of Applied Physiology, 1977, 42, 133 .

${ }^{3} \mathrm{Li}, \mathrm{C}$ C, Introduction to Experimental Statistics. New York, McGraw-Hill, 1964.

+ Åblad, B, et al, Acta Pharmacologica et Toxicologica, 1975, 36, suppl No 5, $\mathrm{p} 1$.

${ }^{5}$ Johnsson, G, Regardh, C G, and Sôlvell, L, Acta Pharmacologica et Toxicolcgica, 1975, 36, suppl No 5, p 31 .

'Douglas-Jones, A P, and Cruickshank, J M, British Medical fournal, 1976, $1,990$.

${ }^{7}$ Bühler, F R, et al, Australian and New Zealand Fournal of Medicine, 1976, 6, suppl No 3, p 37.

(Accepted 22 March 1978)

\title{
Simplified oesophageal transection for bleeding varices
}

\author{
GEORGE W JOHNSTON
}

British Medical fournal, 1978, 1, 1388-1391

\section{Summary and conclusions}

Thirty patients with bleeding oesophageal varices were treated by oesophageal transection using the SPTU gun. Any form of shunt was contraindicated in all the patients. Twelve operations were done as urgent procedures within 36 hours of haemorrhage. The overall operative mortality rate was $10 \%$, and there were two late deaths during follow-up, which has so far extended from two

Royal Victoria Hospital, Belfast

GEORGE W JOHNSTON, MCH, FRCS, consultant surgeon months to two years. Three of the patients had recurrent bleeding, and residual varices were probably the source in two. There were no cases of portal systemic encephalopathy.

Although the follow-up is too short to allow any definite conclusions, these early results suggest that oesophageal transection with the SPTU gun may be useful in the large proportion of patients in whom injection sclerotherapy, shunt surgery, or conservative treatment is inappropriate.

\section{Introduction}

Since Whipple ${ }^{1}$ introduced the Eck fistula into clinical medicine more than 30 years ago, portacaval shunt has been the most popular operation for portal hypertension. About one-third of 
all patients shunted develop symptoms of portal systemic encephalopathy within five years, however, and this fact, together with the lack of evidence that the operation adds significantly to longevity, has led to a decline in its popularity. The Warren" and Inokuchi ${ }^{3}$ selective decompression procedures probably reduce the incidence of post-shunt encephalopathy, but these operations are technically more difficult to perform than a standard portacaval shunt and carry a higher operative mortality. Moreover, there is little place for any form of shunt in an emergency, in the presence of diabetes, in patients with Child's grade C liver dysfunction, or in older patients. Thus, there is a search for alternative methods of managing patients in whom shunts are contraindicated. This article describes the early results of a simplified method of oesophageal transection using the SPTU gun in a series of 30 patients with bleeding varices.

\section{Technique}

The suturing apparatus used in the series was the SPTU universal gun with four interchangeable heads. It is a modification of the original model produced in 1964 by scientists in the USSR for circular stapling of rectal and oesophageal anastomoses. A decade later Van $\mathrm{Kemmel}^{4}$ conceived the idea of using the instrument for oesophageal transection in the management of bleeding oesophageal varices.

When varices are shown to be the source of haemorrhage, oesophageal tamponade is instigated to stop bleeding and allow time for resuscitation and more adequate investigation and preparation of the patient for operation. Since the Sengstaken-Blakemore tube controls bleeding in most patients there is little indication for emergency surgery, and at least 24 hours can be used to start sterilisation of the bowel, correct coagulation problems, and get the patient haemodynamically stable.

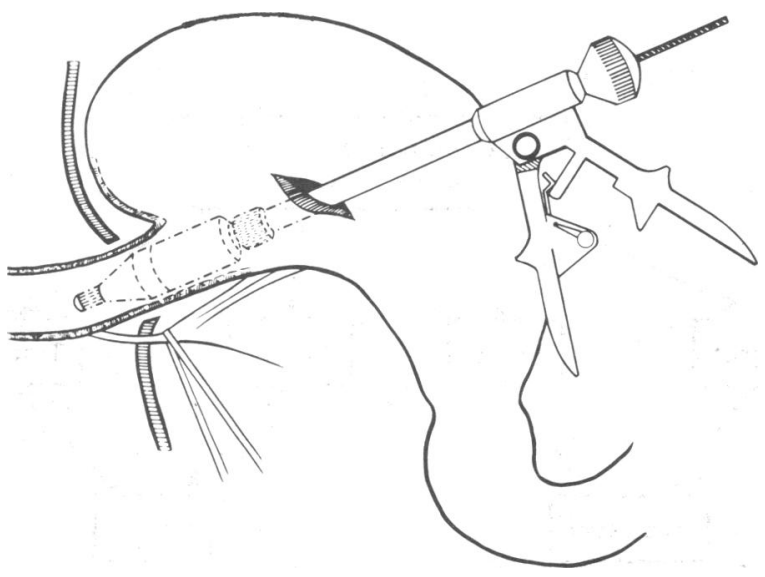

FIG 1-Insertion of gun into lower oesophagus via anterior gastrotomy. Anterior vagus is protected in a sling.

At operation the abdomen is generally opened through a midline epigastric incision and the diagnosis confirmed. The peritoneum in front of the oesophagus is divided transversely to expose the phrenooesophageal ligament, which is brushed upwards, exposing the oesophagus. It is often stated that this is difficult and carries a high risk of serious haemorrhage in patients with portal hypertension, but this has not been our experience. Certainly, two or three large perioesophageal veins usually need ligation, and the left gastric vein should also be ligated at the upper border of the pancreas. In the earlier cases we omitted this last step, but now it is a routine part of the operation and was used in the last 19 patients in the series. Normally both vagal nerves are preserved, but the anterior one can be sacrificed at transection without causing any postoperative problems this was technically unavoidable in eight of our patients. After the oesophagus has been mobilised for about $5 \mathrm{~cm}$, a small anterio gastrotomy is made and the nozzle of the gun carefully advanced into the lower oesophagus (fig 1). The $26-\mathrm{mm}$ diameter head and the 5.5-mm staples have proved ideal for the average adolescent or adult oesophagus.

By an adjusting nut in the handle of the gun, the conical head that acts as an anvil is separated from the cylindrical body which carries the stapling apparatus and guillotine. A stout linen ligature is then passed around the oesophagus and tied to introduce a flange of fullthickness oesophageal wall into the gap between the two sections of the gun (fig 2). Initially, we placed this ligature about $1.5-2.5 \mathrm{~cm}$ above the cardia, but in later cases in the series we endeavoured to do the transection just immediately above the cardia, a factor which has possibly reduced the incidence of postoperative dysphagia. With the flange of oesophageal wall in position, the gap between the two portions in the head of the gun is reduced to less than $2.5 \mathrm{~mm}$ and the trigger pulled to complete the transection. Simultaneously the gun resects a ring of full thickness oesophageal wall and reanastomoses the oesophagus, using 12 tantalum staples. After transection the conical head of the gun is slackened off for about $2-3 \mathrm{~cm}$ and it is then simple

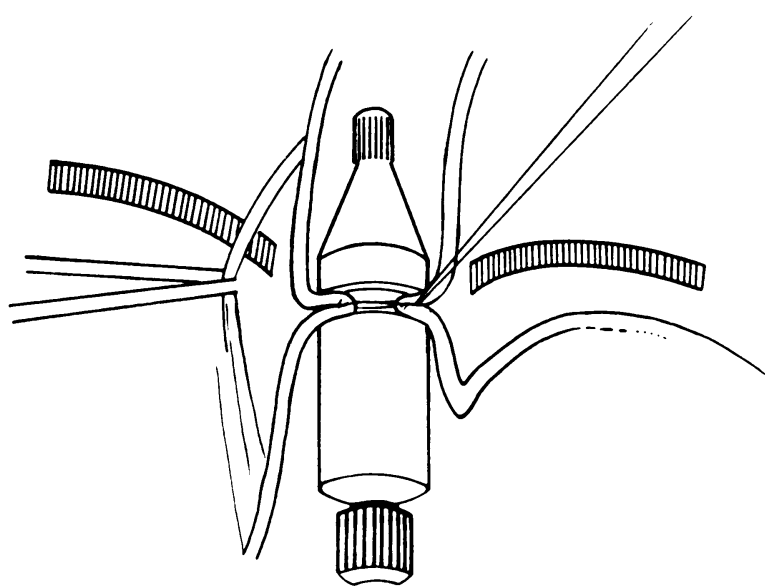

FIG 2-Ligature is tied just above cardia, invaginating a flange of oesophageal wall between the two parts of the gun.

to withdraw the $26-\mathrm{mm}$ head through the newly formed anastomosis. A finger is introduced through the gastrotomy to confirm the satisfactory nature of the suture line and to direct a nasogastric tube into the stomach for postoperative decompression over the next 24-48 hours. The gastrotomy wound is closed in two layers and usually five or six uninterrupted linen sutures are used to reinforce the oesophageal anastomosis anteriorly. After operation oral fluids are routinely withheld for five days. Early in the series gastrografin swallow was carried out on the fifth day, before allowing oral intake, but this precaution was omitted in most of the last 18 cases.

When indicated, additional operative procedures may be carried out. Thus, three of our patients underwent splenectomy and another had splenic artery ligation because of severe hypersplenism. Two patients had truncal vagotomy and gastrojejunostomy carried out at the same time for associated duodenal ulceration. Two patients with incisional hernias and one with an umbilical hernia had them repaired, but, although three others had hiatus hernias, fundoplication was not attempted since it would have been technically difficult after transection. One patient had a palative wedge resection of a primary hepatoma of liver.

\section{Results and comment}

There were 15 men and 15 women in the series, with a mean age of 55 years (age range 14-80). Any form of shunt was contraindicated in all patients. With Child's ${ }^{5}$ classification into minimal, moderate, and advanced liver dysfunction categories, there were 15 grade $A$, three grade $B$, and 12 grade $C$ patients. The 15 grade $A$ patients with good liver function were unsuitable for shunt as four of them had extrahepatic block with no veins suitable for anastomosis, one had juvenile cirrhosis, and the average age of the other 10 was 70 . Five of these grade $\mathrm{A}$ patients also underwent transection as an emergency, and any form of shunt would have been unwise.

Four patients had extrahepatic block alone and one other patient had portal veint thrombosis in addition to micronodular cirrhosis 
(table I). The remainder had cirrhosis of varying types. Eight had alcoholic cirrhosis and two of these also had severe alcoholic hepatitis. In four others chronic active hepatitis was the basis of their cirrhosis, and the remainder had either micronodular or macronodular cirrhosis of unknown cause.

In all patients, varices were shown to be the source of bleeding, although two patients had associated duodenal ulceration and three patients had hiatus hernias. Twelve of the transections were carried out as urgent operations within 36 hours of the bleeding episode, haemorrhage having been controlled initially by oesophageal tamponade.

TABLE I-Details of patients treated by oesophageal transection

\begin{tabular}{|c|c|c|c|c|c|}
\hline Obstruction & $\begin{array}{c}\text { No of } \\
\text { patients }\end{array}$ & $\begin{array}{c}\text { Average } \\
\text { age } \\
\text { (years) }\end{array}$ & $\begin{array}{c}\text { No of } \\
\text { emergency } \\
\text { operations }\end{array}$ & $\begin{array}{c}\text { No of } \\
\text { operative } \\
\text { deaths }\end{array}$ & $\begin{array}{l}\text { No of } \\
\text { late } \\
\text { deaths }\end{array}$ \\
\hline \multirow{2}{*}{$\begin{array}{l}\text { Intrahepatic } \\
\begin{array}{l}\text { Extrahepatic } \\
\text { Intrahepatic and } \\
\text { extrahepatic }\end{array}\end{array}$} & $\begin{array}{r}25 \\
4\end{array}$ & $\begin{array}{l}58 \\
38\end{array}$ & $\begin{array}{r}10 \\
1\end{array}$ & $\begin{array}{l}3 \\
0\end{array}$ & $\begin{array}{l}2 \\
0\end{array}$ \\
\hline & 1 & 48 & 1 & 0 & 0 \\
\hline Total & 30 & 55 & 12 & 3 & 2 \\
\hline
\end{tabular}

There were three operative deaths in the series, all occurring about three weeks after surgery. Two of the deaths occurred in the group that had emergency transection, and both these patients had grade $\mathrm{C}$ liver dysfunction. One died from respiratory failure secondary to longstanding pulmonary fibrosis from tuberculosis and the other from multiple organ failure, starting with hepatorenal failure. The third patient who died was a 48-year-old diabetic with micronodular cirrhosis. He had a fever after operation and gradually deteriorated and died from Gram-negative septicaemia secondary to low-grade septic peritonitis, although two postoperative cultures of the peritoneal fluid had been sterile.

\section{COMPLICATIONS}

There were several perioperative complications, but none of these were fatal. The 15-year-old boy with juvenile cirrhosis developed a temporary anastomotic leak and the subsequent fistula took some weeks to seal off. Unknown to the staff this patient had been taking large quantities of oral fluids from the first day after operation. Another patient, a 60-year-old alcoholic cirrhotic who was just recovering from radiotherapy for carcinoma of the larynx, developed major bleeding from the site of transection at the time of surgery. The anterior gastrotomy was immediately extended and the posterior suture line reinforced with a few interrupted catgut sutures, which controlled the bleeding adequately. A 45-year-old woman with primary biliary cirrhosis developed unexplained unilateral foot drop six days after operation, a complication evidently not uncommon after hepatic transplantation. The cause was uncertain; it did not seem to be due to peroneal nerve pressure at the time of surgery.

Most of the patients developed mild dysphagia for a few weeks after surgery. Only five patients required dilatation of the oesophagus, one patient three times, one twice, and the other three only once. In retrospect, I doubt whether all of these dilatations were necessary, since in two patients the endoscope passed through the stricture without significant hold-up. Four of the first 12 patients in the series underwent dilatation but only one of the subsequent 18 . This reduction in the incidence of dilatation may represent more patience on the part of the surgeon, allowing deglutition to act as its own dilator, or perhaps reflect the change in technique in the later cases, where the oesophagus was divided just immediately above the oesophagogastric junction. Perhaps the earlier higher transections left a functioning but isolated cardiac sphincter which failed to act in co-ordination with deglutition. Unfortunately, the results of our postoperative oesophageal pressure studies were inconclusive on this point.

At the follow-up clinics a few patients complained of heartburn, which is not surprising in view of the serious interference with the normal antireflux mechanism. Thus, we advise all patients to take one of the alginic acid preparations routinely after each meal and nightly before retiring.

Early postoperative bleeding occurred in one 50 -year-old patient with grade $C$ dysfunction with cirrhosis; a persistent mild ooze lasted for about one week after surgery before stopping spontaneously.
Late bleeding occurred in three other patients during follow-up, which so far has extended from two months to two years (average 13 months). In one patient the source of bleeding was a stomal ulcer after truncal vagotomy and gastrojejunostomy; this responded completely to a course of cimetidine. Another patient who spent most of his waking hours drinking in public houses was readmitted with bleeding twice, but in spite of endoscopy within 12 hours no source of bleeding was found and haemorrhage ceased spontaneously on both occasions. The third patient was the man with laryngeal carcinoma who had bled from the suture line at surgery. He was subsequently readmitted with further bleeding, and on endoscopy small varices were found and were presumably the source of bleeding; injection sclerotherapy was carried out. All three patients with recurrent bleeding were still alive at the time of writing.

\section{LATE DEATHS}

There were two late deaths in the series, both occurring in patients with grade $\mathrm{C}$ dysfunction. The patient with primary hepatoma died at home from liver failure six weeks after surgery. A further patient with severe alcoholic hepatitis started drinking heavily immediately after discharge and died at home from reactivation of the hepatitis three and a half months after operation.

None of the 25 surviving patients developed portal systemic encephalopathy.

\section{Discussion}

Centres concerned with the management of bleeding oesophageal varices often adhere too rigidly to a single method of treatment which happens to enjoy popularity at the time. Ideally, there should be several different lines of management, each matched to the individual patient. Thus, after 12 to 36 hours spent in resuscitation, investigation, and initial treatment, patients may be allocated to one of four treatment categories on the basis of clinical status (fig 3). Patients with severe jaundice

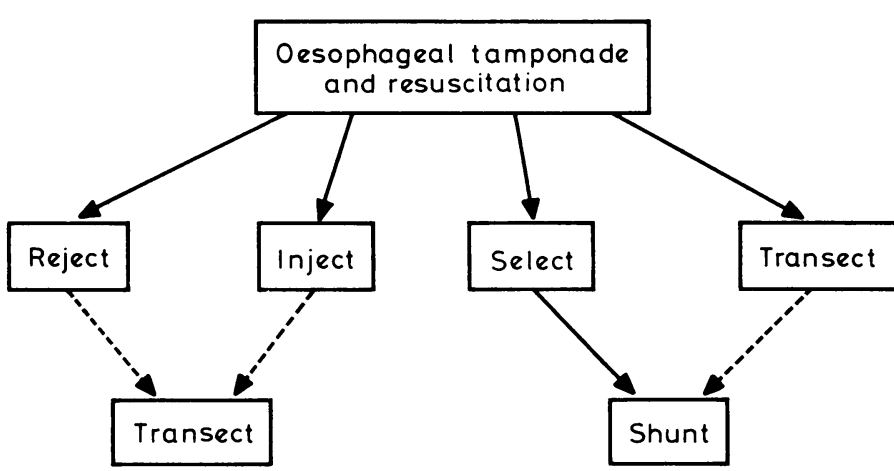

FIG 3-Flow diagram of possible treatment categories following diagnosis of bleeding varices.

and precoma or coma should be rejected for any operative procedure and conservative measures continued. In those with moderate ascites and jaundice it is best to avoid laparotomy and use one of the methods of injection sclerotherapy. ${ }^{6}$ A few patients aged under 50 who have good liver function and stop bleeding do not require urgent operations but should be selected for shunt surgery as a definitive procedure at a later date. After these three groups have been excluded, a large proportion of patients remain who fall into the transection category.

The idea of direct transoesophageal ligation of varices was pioneered over a quarter of a century ago by Boerema ${ }^{8}$ and Crile. ${ }^{9}$ Although their operation is still widely used, it carries a high risk of oesophageal fistula and recurrent bleeding, both immediately after operation and later. Walker's ${ }^{10}$ method of transection reduces the chance of fistula formation, but it also suffers from the risk of recurrent haemorrhage. Both procedures 
require thoracotomy and carry a mortality rate of around $30^{\circ}{ }_{0}-40^{\circ}{ }_{0}$ (table II). ${ }^{9-19}$ The Boerema button ${ }^{20}$ and Prioton clip ${ }^{21}$ methods of oesophageal transection have the advantage of an abdominal approach and also transect the full thickness of the oesophageal wall. But the high morbidity from stricture formation detracts from the simplicity and low mortality of these procedures. ${ }^{22}$ By using the Russian SPTU gun, which produces immediate mucosal apposition, Van Kemmal ${ }^{4}$ found that he could reduce the incidence of stricture formation.

TABLE II-Transthoracic oesophageal transections and ligations

\begin{tabular}{|c|c|c|}
\hline Authors & No of patients & "., Mortality \\
\hline 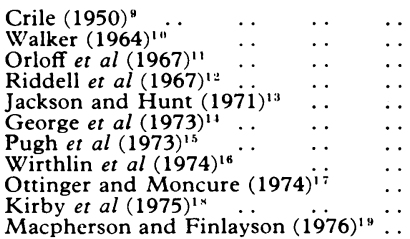 & $\begin{array}{r}7 \\
16 \\
28 \\
20 \\
58 \\
30 \\
38 \\
55 \\
72 \\
54 \\
17\end{array}$ & $\begin{array}{l}0 \\
37 \\
46 \\
25 \\
45 \\
53 \\
55 \\
29 \\
50 \\
22 \\
24\end{array}$ \\
\hline Total & 395 & 39 \\
\hline
\end{tabular}

The abdominal approach has many advantages over thoracotomy. Firstly, the operation can be completed much more rapidly and with less blood loss. Secondly, it permits inspection and biopsy of the liver and allows the surgeon to deal with any associated disease such as peptic ulceration, hypersplenism, etc. Thirdly, it allows access for ligation of the left gastric vein and the perioesophageal collateral vessels, thereby reducing the chance of recurrent bleeding. Finally, it enables the surgeon to evacuate the blood clots from the stomach and thus reduces the nitrogenous load on the liver.

It is difficult to obtain reliable figures about the incidence of recurrent bleeding after either the Boerema-Crile or Walker transections. About one in five of the survivors seem to rebleed within one year and about one in three have further haemorrhage within five years. One would expect better results after gun transection, in which the full thickness of the oesophageal wall is divided and the large collateral vessels are also ligated. In this series the maximum follow-up is only two years, and obviously more time is required before it becomes clear how good the results are. Already two patients have had non-fatal recurrent bleeding, which may well have been from residual varices, although the site of bleeding was not shown at endoscopy. In Van Kemmel's ${ }^{23}$ series of 37 transections three patients had recurrent bleeding from varices at the cardia during a maximum follow-up of eight years. The disappearance of varices on postoperative barium studies (fig 4) and at endoscopy is encouraging, but obviously transection of the oesophagus cannot prevent haemorrhage from gastric varices. Like Walker, ${ }^{10}$ however, I believe that this is an uncommon source of bleeding. Anatomically, only in the lower oesophagus do the veins lie immediately below the mucosa and are therefore more susceptible to the extra strain imposed by the intermittent negative intrathoracic pressure. $^{18}$

Although most patients get minor dysphagia after transection, less than $20^{\circ}{ }_{0}$ have required active treatment, and the lower siting of the anastomosis is expected further to reduce the problem. Where interference has been necessary the strictures dilated easily without bleeding, using Eder-Puestow dilators under diazepam sedation.

Since the procedure diverts no blood from the liver an increase in the incidence of portal systemic encephalopathy would not be expected postoperatively. This has been borne out in this series, although 21 of the patients were aged over 50 and

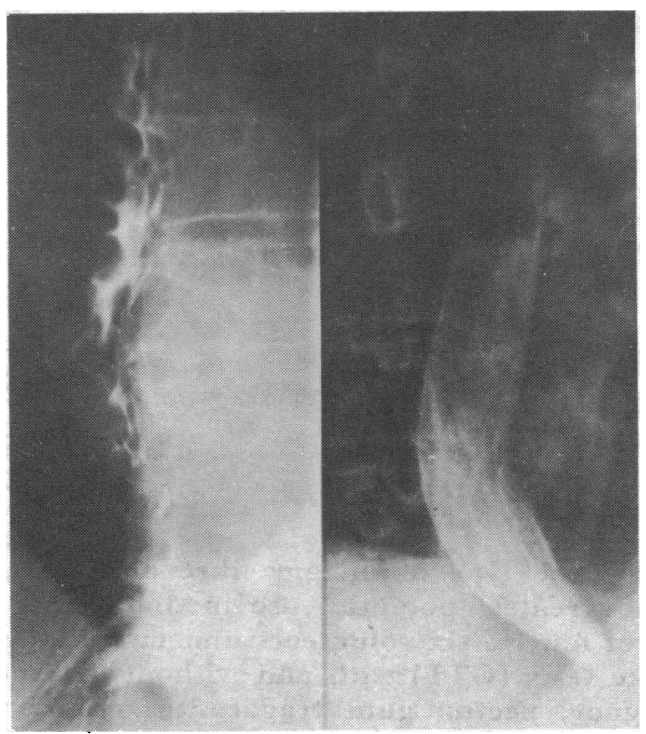

FIG 4-Barium study of oesophagus before (left) and two weeks after (right) emergency transection in a 71 -year-old woman with cirrhosis.

seven were over 70 . This absence of postoperative encephalopathy should encourage more careful selection of patients for any form of shunt and make this method of oesophageal transection particularly attractive for patients with portal hypertension due to schistosomiasis, where post-shunt encephalopathy presents such a serious problem.

The average follow-up in this series lasted only 13 months and therefore $I$ am cautious about predicting the future. Certainly, the $10^{\circ}$ o operative mortality rate in people in whom shunts are contraindicated, the low incidence of recurrent bleeding, and the absence of portal systemic encephalopathy are encouraging signs for the future.

\section{References}

1 Whipple, A O, Annals of Surgery, 1945, 122, 449.

2 Warren, W D, Zeppa, R, and Fomon, J J, Annals of Surgery, 1967, 166, 437.

${ }^{3}$ Inokuchi, K, et al, Surgery, 1975, 78, 628

4 Van Kemmel, M, Nouvelle Presse Médicale, 1974, 5, 1123.

${ }^{5}$ Child, C G, The Liver and Portal Hypertension, p 50. Philadelphia and London, Saunders, 1964

' Johnston, G W, and Rodgers, H W, British fournal of Surgery, 1973, 60, 797.

' Lunderquist, A, and Vang, J, New England fournal of Medicine, 1974, 291, 646.

${ }^{8}$ Boerema, I, Nederlands Tiidschrift voor Geneeskunde, 1949, 93, 4174.

${ }^{9}$ Crile, G S, Archives of Surgery, 1950, 61, 654.

${ }^{10}$ Walker, R M, Surgery, Gynecology, and Obstetrics, 1964, 118, 323.

11 Orloff, M J, Annals of Surgery, 1967, 166, 456.

${ }^{12}$ Riddell, A G, Brown, G J A, and Reed, P C, The Liver, p 382. London, Butterworths, 1967.

13 Jackson, R L R, and Hunt, A H, British fournal of Surgery, 1971, 58, 205.

14 George, P, et al, British fournal of Surgery, 1973, 60, 635.

${ }_{15}$ Pugh, R N H, et al, British fournal of Surgery, 1973, 60, 646.

${ }^{16}$ Wirthlin, L S, Linton, R R, and Ellis, D S, Archives of Surgery, 1974, 109, 688.

17 Ottinger, L W, and Moncure, A C, Annals of Surgery, 1974, 179, 35.

${ }^{18}$ Kirby, R, Burke, F D, and Jones, J D T, Annals of the Royal College of Surgeons of England, 1975, 57, 148.

${ }^{19}$ Macpherson, A I S, and Finlayson, N D C, Fournal of the Royal College of Surgeons of Edinburgh, 1976, 21, 90.

${ }^{20}$ Boerema, I, Klopper, P J, and Holscher, A A, Surgery, 1970, 67, 409.

21 Prioton, J B, Annales de Chirurgie, 1973, 27, 343.

${ }^{22}$ Johnston, G W, and Kelly, J M, British Fournal of Surgery, 1976, 63, 117.

${ }^{23}$ Van Kemmel, M, personal communication, 1977.

(Accepted 29 March 1978) 